\title{
Experimental Comparison Between Wire Mesh and Electrical Capacitance Tomography Sensors to Predict a Two-Phase Flow Behaviour and Patterns in Inclined Pipe
}

\author{
Ali I. Hameed ${ }^{1}$, Lokman A. Abdulkareem ${ }^{2,3}$, Raid A. Mahmood ${ }^{1,4}$. \\ ${ }^{1}$ Department of Mechanical Engineering, University of Zakho, Zakho City 12, \\ Kurdistan Region of Iraq, Iraq \\ ${ }^{2}$ Department of Petroleum Engineering, University of Zakho, Zakho City 12, \\ Kurdistan Region of Iraq, Iraq \\ ${ }^{3}$ Institute of Fluid Dynamics, Helmholtz-Zentrum Dresden-Rossendorf, Dresden \\ 01328, Germany \\ ${ }^{4}$ School of Mechanical and Electrical Engineering, University of Southern \\ Queensland, Toowoomba 4350, Australia
}

\begin{abstract}
Ali I. Hameed ${ }^{1}$, email: Ali.Ibrahim@staff.uoz.edu.krd
Abstract. Two-phase flow behaviour and its flow patterns have a significant effect in many applications in industry. Oil-gas is one of the two-phase flow types that have many applications in petroleum and power stations. An oil-gas two-phase flow behaviour and flow patterns have been investigated in an inclined pipe using two different tomography sensors: Wire Mesh sensor (WMS) and Electrical Capacitance Tomography (ECT). A special experimental facility was designed and built to operate the tow-phase flow application in the inclined pipe with the various angle of inclination. A set of experimental data were collected using operating conditions which covered a two-phase flow range of superficial velocity of gas (Usl) from 0.05 to $0.52 \mathrm{~m} / \mathrm{s}$ and superficial velocity of liquid (Usg) from 0.05 to $4.7 \mathrm{~m} / \mathrm{s}$ at atmospheric pressure and room temperature. Three inclined angles to change the pipe's inclination 45, 60, and 80-degree were applied in the experiments. The Comparison between the Wire Mesh Sensor (WMS) and Electrical Capacitance Tomography (ECT) was completed experimentally. The results revealed that there is a good agreement between the two sensors, however; the WMS had a higher frequency which was calculated 1000 frames per second compared with the ECT which worked at 200 frames per second.
\end{abstract}

Keywords. two-phase flow patterns in pipes, oil-gas flow patterns, Wire Mesh sensor (WMS), Electrical Capacitance Tomography (ECT).

\section{Introduction}

Multiphase flow has many applications and has many forms. One of the most widely used is a gasliquid two-phase flow. The gas-liquid two-phase flow can be found in vertical, horizontal, and inclined pipes.[1] It plays a significant role in a wide range of manufacturing and industry such as in boilers [2], petroleum industry chemical plants, heat transfer devices [3], nuclear reactor technology, and geothermal energy production.Many studies investigated the two-phase flow behavior and its flow development, focusing on flow patterns, pressure drop and system performance. [4] carried experimental and numerical investigation of two-phase flow orientation and direction change. The author reported that the orientation of the flow direction of the two-phase flow has a significant effect on the flow pattern change and flow behavior.

Two-phase flow patterns represent the behavior of the two-phase flow and can be found in many forms which depend on the operating conditions. The two-phase flow pattern influences the performance of some industry devices such as vertical flash tank separators for the liquid separation $[5],[6]$. 
Many techniques were used to determine the void fraction $(\alpha)$ of the flow which were used to specify flow regimes such as Wire-Mesh Sensor (WMS) [6], Electrical Capacitance Tomography (ECT) [8], X-ray Tomography [9], Ultrasound [10], and Measurement techniques used are Electrical Capacitance Tomography (ECT), wire mesh sensor (WMS), in addition to advanced measurement techniques were employed to measure the time series void fraction like L. A. Abdulkareem[11].V.A.Musa[12] also recognized the concluded flow regimes that occurred considered in the horizontal pipes. Numerously Investigation made studies and clarified the flow in horizontal pipes due to flow regimes thus has observed this phenomenon.According to L.A. Abdulkareem[1] Investigations, it surely shows that based on deviations up to $32^{\circ}$ from vertical, a larger part of data that is involved in these studies was based on the air and water experiments. However, most studies were based on the blend of gas-liquid that flow in a small internal diameter of $25 \mathrm{~mm}$ to $75 \mathrm{~mm}$ respectively. A vast part utilized air and water as working fluids, henceforth studies involving inclined large-diameter multiphase flows are not common.

O. T. Kajero [13] one of the recent additions to the scanned database, however, they conducted steady-state and transient experiments of water and gas, oil and water, and oil-water multiphase flow. Using an inclinable pipe that is transparent and has a length of $11 \mathrm{~mm}$ and also $150 \mathrm{~mm}$ diameter. The inclinable pipe with pipe inclination varying from $0^{\circ}$ vertical to $92^{\circ}$ over a vast range of flow rates. Above all is further utilized by processing, petroleum, geothermal, and other related industries.Flow pattern identification, based on an analysis of void fraction, was carried out by Jones and Zuber [14]. In this case for the two-phase air-water mixture flowing through vertical rectangular test section as the working flow. Henceforth the technique of high X-ray energy absorption for pattern identification was utilized which comprises dual-beam X-ray devices, that is passing through the two-phase mixture and the other on a reference sample.

The time series calculation method is used as an adjunct to identify and analyses the vertical pipe flow pattern. In addition to this, a spatial distribution phase section resolved information and time is provided by the WMS. Henceforth the time series of cross-sectional averaged void fraction obtained from WMS tomography have been illustrated in [12].

Therefore, the study clearly explains the flow regimes for gas-liquid flow using PDF the holding up of liquid in the time-series domain and PSD is used for flow identification in transparent inclined pipes,Abdulkareem [15]. A common technique was developed for the non-intrusive imaging technology and it was used to visualize the distribution of cross-sectional permittivity, for contents in a dielectric pipe regarding the capacitance of the measured data. This is what refers to electrical capacitance tomography (ECT), according to Xie et al (1989) [16].The following important factors are; high-speed captions, lower cost, and non-intrusive sensor suitability for different pipe sizes. Therefore, ECT is considered to be a promising industrial process for tomography. Being the proven employed best technique in multiphase flows with relatively non conducting mixtures, the ECT is also has proven relatively to be an exceptional technique.To obtain images in the ECT technique, the difference in electrical permittivity of the two phases should be considered.Thus it is exploited by consecutive measurement of dispersed void fraction according to: Xie et al (1995) [17], Williams and Beck (1995)[18].The completed study of WMS in vertical pipes of $6.7 \mathrm{~cm}$ diameter using air-water blend fluid concluded that there will be an ability to manage the full pipe flow; therefore, the outcome was data in form of cross-sectional void fraction in the time series according to Azzopardi et al [19].

The understanding of the two-phase flow properties depends on the understanding and knowledge of the flow regimes that happened. The right prognostication of two-phase flow regimes is a good beginning for designing any systems that save power and decrease collapse by determining that gas and liquid void fraction. another side about this, learning about the inclined pipe force as such flow is also useful in the design of pipeline like oil pipe. The present project examining the Inclined Riser effect on the flow regimes consists of gas and the oil silicone into incline pipe deference angle like 45,60, and80degree with $6 \mathrm{~m}$ length and $6.7 \mathrm{~cm}$ inner diameter of the pipe, it is using two measurement techniques such as WMS and ECT as determining the void fraction. 


\section{Experiment Design}

The current experiment was completed with a mixture consisting of silicone oil and air as a two-phase flow which flowed up direction in a pipe of internal diameter $67 \mathrm{~mm}$ and 6-meter length. as shown in Figure 1. The flow was tested in different orientations varied from 40-degrees to 90-degrees (near to vertical flow). Series of runs were carried out to category the flow pattern of silicone oil-air flow at superficial velocities of air changed from 0.05 to $4.9 \mathrm{~m} / \mathrm{s}$ and fixed values of liquid superficial velocities of $\mathrm{f} 0.052$, and $0.524 \mathrm{~m} / \mathrm{s}$.

As appeared from the mentioned figure, two capacitance sensors are joined respectively, Electrical Capacitance Technique ECT at a distance of $5.5 \mathrm{~m}$ that measured from the entering mixture, and the Wire Mish Sensor WMS is set up cross-sectionally above the ECT directly. The facility of the present investigation included a mixture utilized to mix the component of the two phases which entered the pipe and exited to a separator device to separate the air from the mixture, where the air is extracted to the atmosphere while the remained blend represented with silicone oil entered to a storage tank where was kept at constant room temperature at $27 \mathrm{C}$. As a loop, the arrived silicone oil from the storage tank enters through a rotameter type (Fisher 2000, Fisher Controls Limited, England) to record its volumetric flow rate, then it is directed using a centrifugal pump type (Flowserve, model 32WJ200) to the mixing device again for meeting the air which also came from a central compressor, also, its volumetric flow rate is measured by a special rotameter type (KDG, $0-400 \mathrm{~L} / \mathrm{min}$, France). The distance between the mixing device and the sensors was sufficient to provide the stability to the flow and reach the developed flow condition. At the separator device, silicone oil falls due to the gravity force into the storage tank where the air is discharged from the top point of the separator.

A strong moving frame with a limited rotation angle is exploited to keep the pipe stable while is tested with high velocities of air and liquid. The test was performed at atmospheric pressure and room temperature near $27 \mathrm{C}$. The void fractions that are aggregated from ECT and WMS are recorded at each pipe orientation at the same condition regarding the two phases' flow rates.

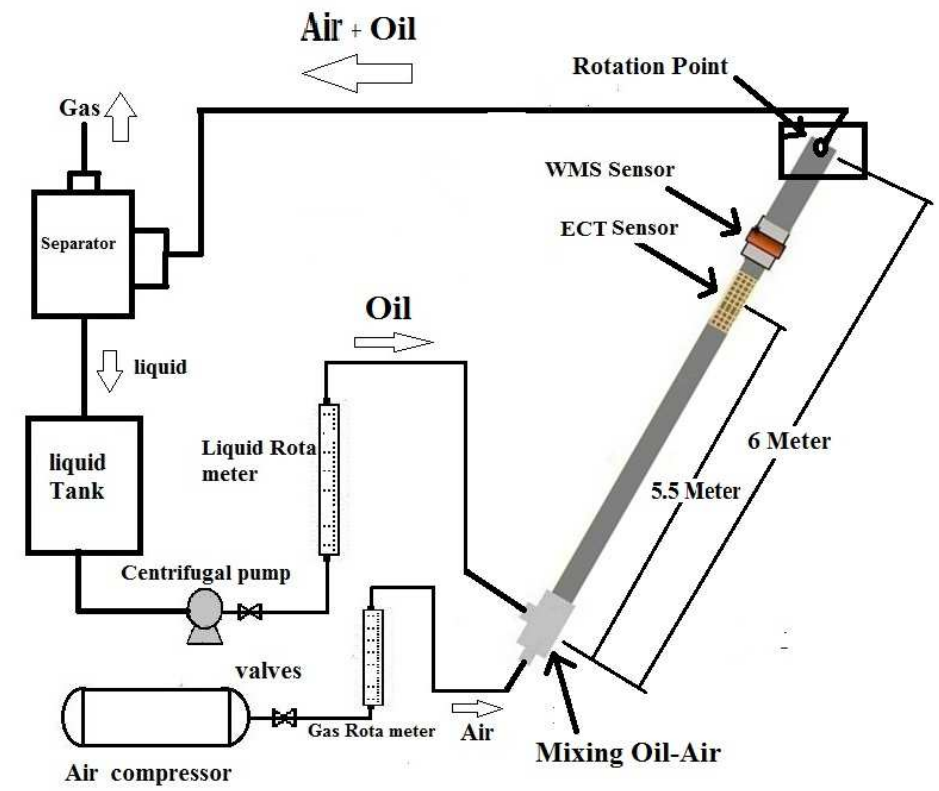

Figure 1: Schematic diagram of the test. 


\section{Results and discussion}

A set of data have been recorded using some specific techniques and sensors, such as wire mesh sensor, and ECT, they were joined to the experiment structure. The data are taken under the test operation condition as follows; at constant values of Usl ranged from 0.05 to $0.52 \mathrm{~m} / \mathrm{s}$ with different values of Usg ranged from 0.05 to $4.7 \mathrm{~m} / \mathrm{s}$ at atmospheric pressure and room temperature. three pipe orientations represent 45,60 , and 80 -degree angles that have been tested under the same operation condition for each position. The present test is carried out with a blend of silicone oil and airflow in a transparent pipe of an internal diameter of $67 \mathrm{~mm}$ and $6 \mathrm{~m}$ in length. The experiment data has recorded at the entry liquid superficial velocities (Usl) are changed four times from 0.052 to $0.52 \mathrm{~m} / \mathrm{s}$, and entry gas superficial velocities (Usg) are altered 13 terms from 0.05 to $4.7 \mathrm{~m} / \mathrm{s}$. The comparison between the results of the outcome obtain from both sensors has been performed using the following method; the time series of void fraction and mean void fractions $(\alpha)$. The current part is stated all required details, argument discussion. Some recorded void fractions are deleted due to some problem-related electricity issue and sensor themselves. The judgment of the classification of the two-phase patterns in the current tests isbased on the results of investigators in [1],[11],[15],[20]

\subsection{The analysis of the void fraction ( $\alpha$ ) with time series, and Probability Density Function (PDF)}

At a constant Usl value of $0.05 \mathrm{~m} / \mathrm{s}$; Figure 2 showed the analysis of PDF and void fractions of series at the uniform value of Usg $0.05 \mathrm{~m} / \mathrm{s}$ and Usl values of 0.052 . Section (a) of the previous figure illustrated the results inside the 45-degree pipeline, on one hand, both plots of PDFs that related to ECT and WMS exhibit similar behaviour, where one peak is appearing at a low void fraction near to 0.05 with the maximum value of PDF approached to 0.25 . On the other hand, the analysis of void fractions that arrived from both sensors of time series also showed the same conducts, where all mostly, void fractions have fluctuated at the low values between 0 and $0.3 \mathrm{in} 60 \mathrm{~s}$. No mentioned differences were observed for the PDF plots and the analysis of void fraction between at 60 degrees (sections (c)) and 80-degree pipe orientation (section (e)) of the same figure, where the plots of PDF of both sensors reached the maximum value at near 0.15 and low void fraction value for both sensors.

Bubbly flow is estimated at Usl value of $0.052 \mathrm{~m} / \mathrm{s}$ and Usg value of $0.05 \mathrm{~m} / \mathrm{s}$, regarding the amount of liquid and gas and their velocities, the result seems reasonable due to the low flow rate of gas and the effect of gravity where the pipe is filled with liquid under the low velocity of liquid and bubbles were flowed vertically through the liquid phase. When the value of Usg is increased to $0.3 \mathrm{~m} / \mathrm{s}$ as Figure 3 depicted. The plots and figures 2 of sections ( $a, b$, and $c$ ) showed similar behaviour for both sensors, where the void fractions fluctuated near between 0.05 and 0.7. The PDF plots recorded Wight bases were ranged from 0 to 0.8 of void fraction and presented two peaks at values of 0.02 and 0.05 . The babbly flow pattern altered to slug flow. 

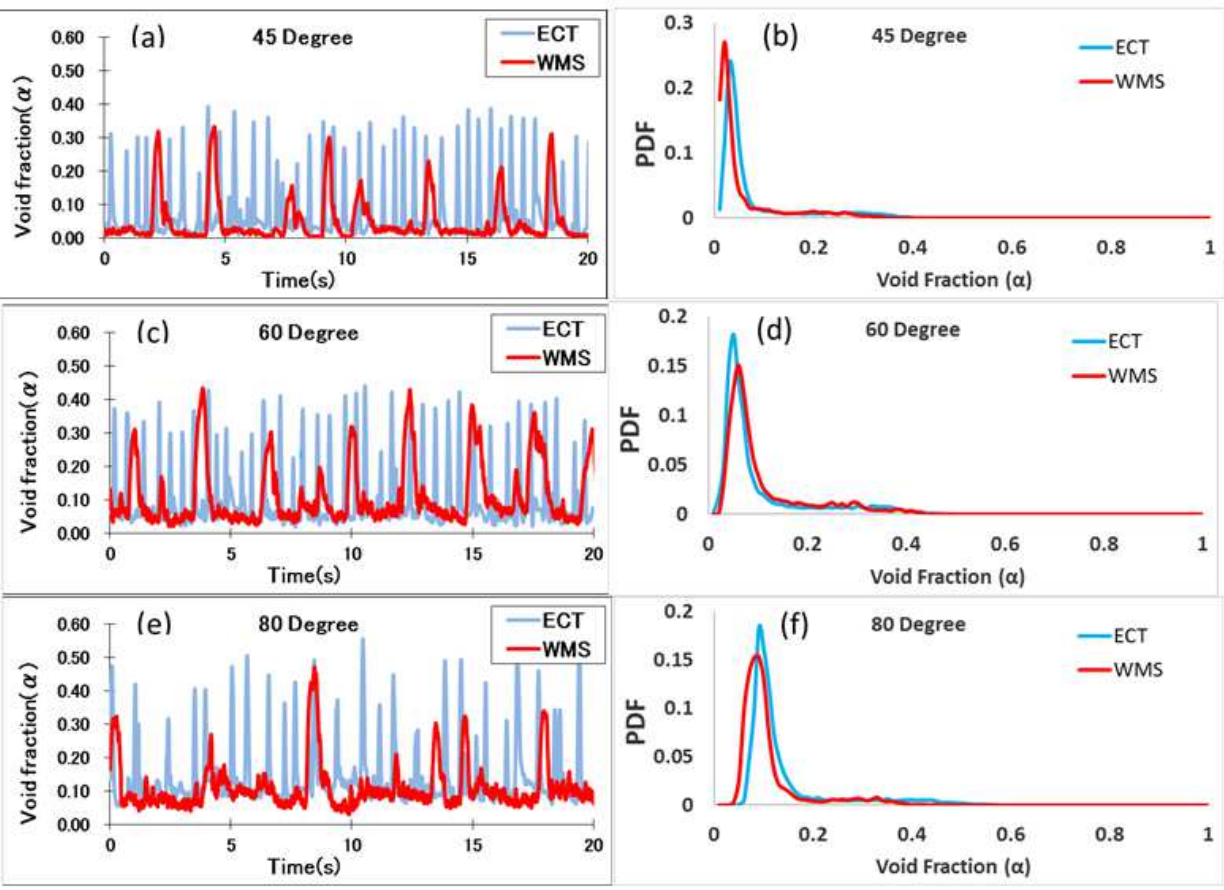

Figure 2: Void fraction of time series, and PDF technique for pipe orientations; 45-degree ( $a$ and $b$ ), 60 -degree (c and d), and 80-degree (e and f) respectively atUs1 $0.052 \mathrm{~m} / \mathrm{s}$ and Usg $0.05 \mathrm{~m} / \mathrm{s}$.

When the value of Usg is raised to $1.3 \mathrm{~m} / \mathrm{s}$ at constant Usl value is $0.052 \mathrm{~m} / \mathrm{s}$, as shown in Figure 3. at the 45,60- and 80-degree pipe flow, it has changed the flow pattern from slug to churn flow. the mean void fraction of time series for both techne WMS and ECT the same value, to 45degree high void fraction about 0.8 , to 60 -degree rise void fraction to near to 1.0 for WMS but for ECT about 0.75 the difference between WMS and ECT near 0.25.to 80 degrees pipe flow, the mean void fraction of time series about 0.85 , the same value between two sensors. The plot of PDF has one peak at void fraction 0.8 (Figure 3(b)), 0.2 void fraction increase slowly the same for WMS and ECT until 0.6 voids fraction sharp raiser after that to decree to zero. See figure $3 \mathrm{~d}$ The ECT at 60 -degree pipe flow the pdf has one at void fraction 0.8 but at WMS have two peak shape waves from 0.6 to 1.0 void fraction and at 80 degrees include pipe flow inlet, it has one peak at void fraction about 0.6 ECT and 0.9 WMS show figure 3(f). In this sort, the amount value of the gas phase is higher than the liquid phase also, this appears as one high peak.

As Show the Figure 5 when the increase Usg value $2.5 \mathrm{~m} / \mathrm{s}$ at constant value Usl $0.052 \mathrm{~m} / \mathrm{s}$. the flow regime is observed churn, do not change flow pattern but change about shape for different orientations. The mean void fraction of time series for both techniques near to 0.9 Figure 5 section (a,c and e), and the PDF chart as high peak at 0,8 void fraction at ECT but WMS sensor do not see peak shows figure 5 section(b) small fluctuate around 0.6 to 0.9 void fraction, at 60 degrees of ECT the pdf curve has one small peak around 0.05at 0.8 void fraction and WMS has a big peak of a plot of PDF near0.15 at 0.9 voids fraction (Figure 5 section (d)).

When the Usg value reached $4.7 \mathrm{~m} / \mathrm{s}$ at constant value Us1 $0.052 \mathrm{~m} / \mathrm{s}$, the flow regime is churn flow, for 45,60 and 80-degree inclined pipe flow. At 45 and 80 degrees, the mean void fraction of the time series with the same value fluctuates near 0.9 Figure 6 (a and e), but at 60-degree high wave near 1.0.The plot of PDF has some difference between both techniques show the Figure 6(d), ECT has a small peak at 0.85 void fraction, WMS has a big peak at 0,9 void fraction. At 45 degrees and 80degree the same value for both techniques near 0.8. Finally, the value of Usg is raised from (to $4.7 \mathrm{~m} / \mathrm{s}$ ) 
at constant Usl. Another pattern is observed. This type has no uniform shape just it is near to churn in shape. It also can be classified by the analysis of PDF; the amount value of gas is higher than of liquid and appears as one large peak in the region between ( 0.5 to 0.8$)$.
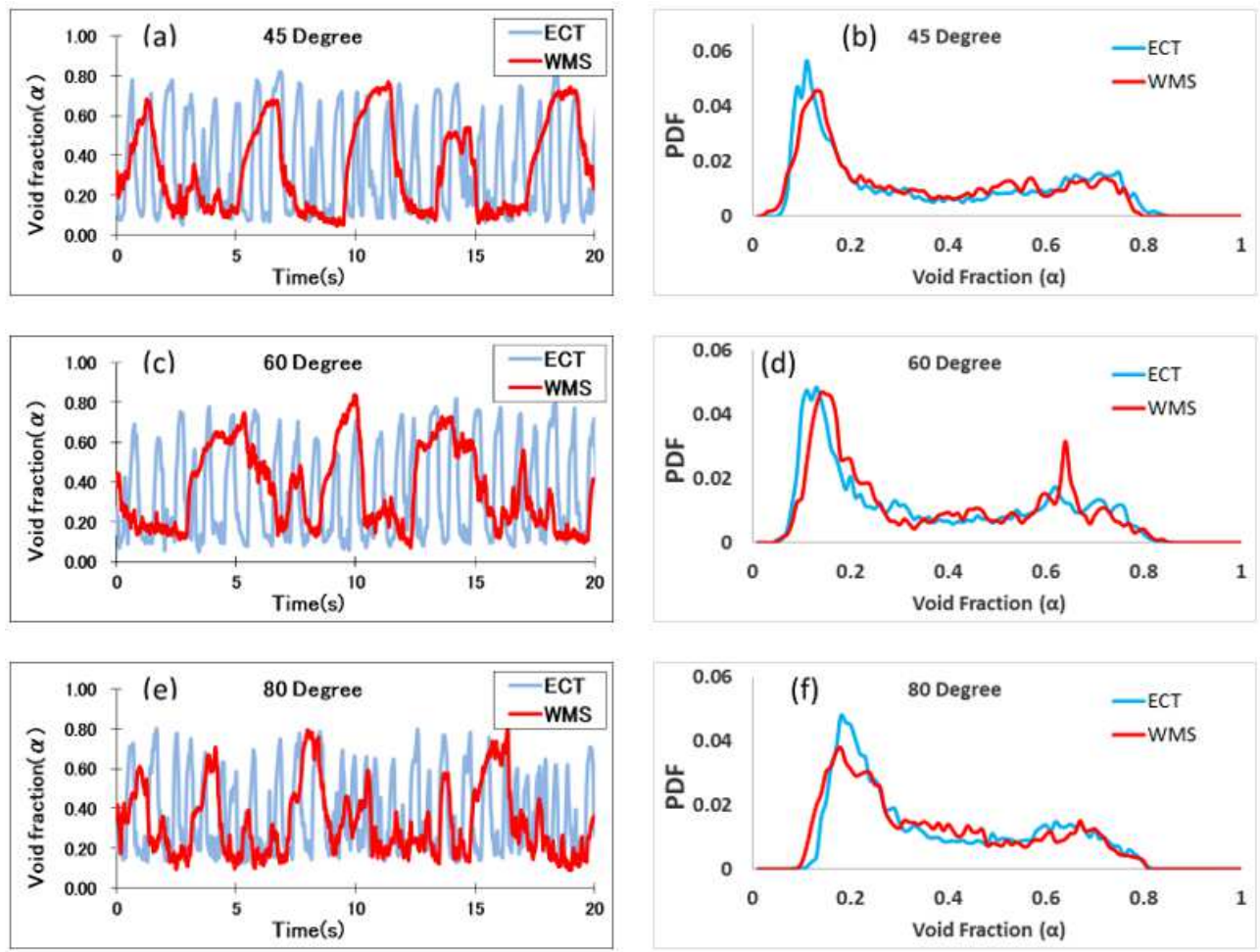

Figure 3: Void fraction of time series, and PDF technique for pipe orientations; 45-degree (a and $b$ ), 60-degree (c and d), and 80-degree (e and f) respectively at Usl $0.052 \mathrm{~m} / \mathrm{s}$ and Usg $0.3 \mathrm{~m} / \mathrm{s}$. 

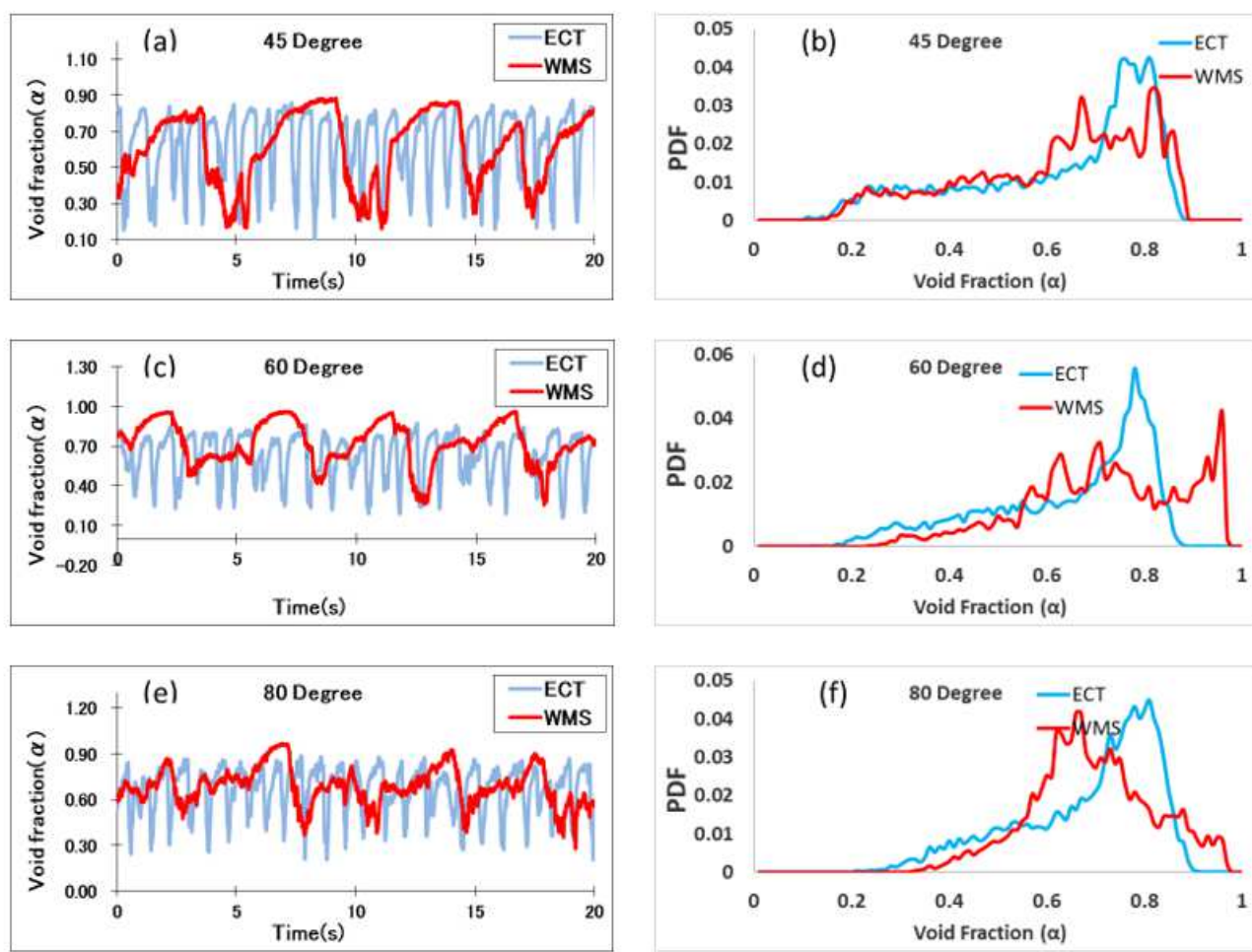

Figure 4: Void fraction of time series, and PDF technique for pipe orientations; 45-degree (a and $b$ ), 60 -degree (c and d), and 80-degree (e and f) respectively at Usl $0.052 \mathrm{~m} / \mathrm{s}$ and Usg $1.3 \mathrm{~m} / \mathrm{s}$.
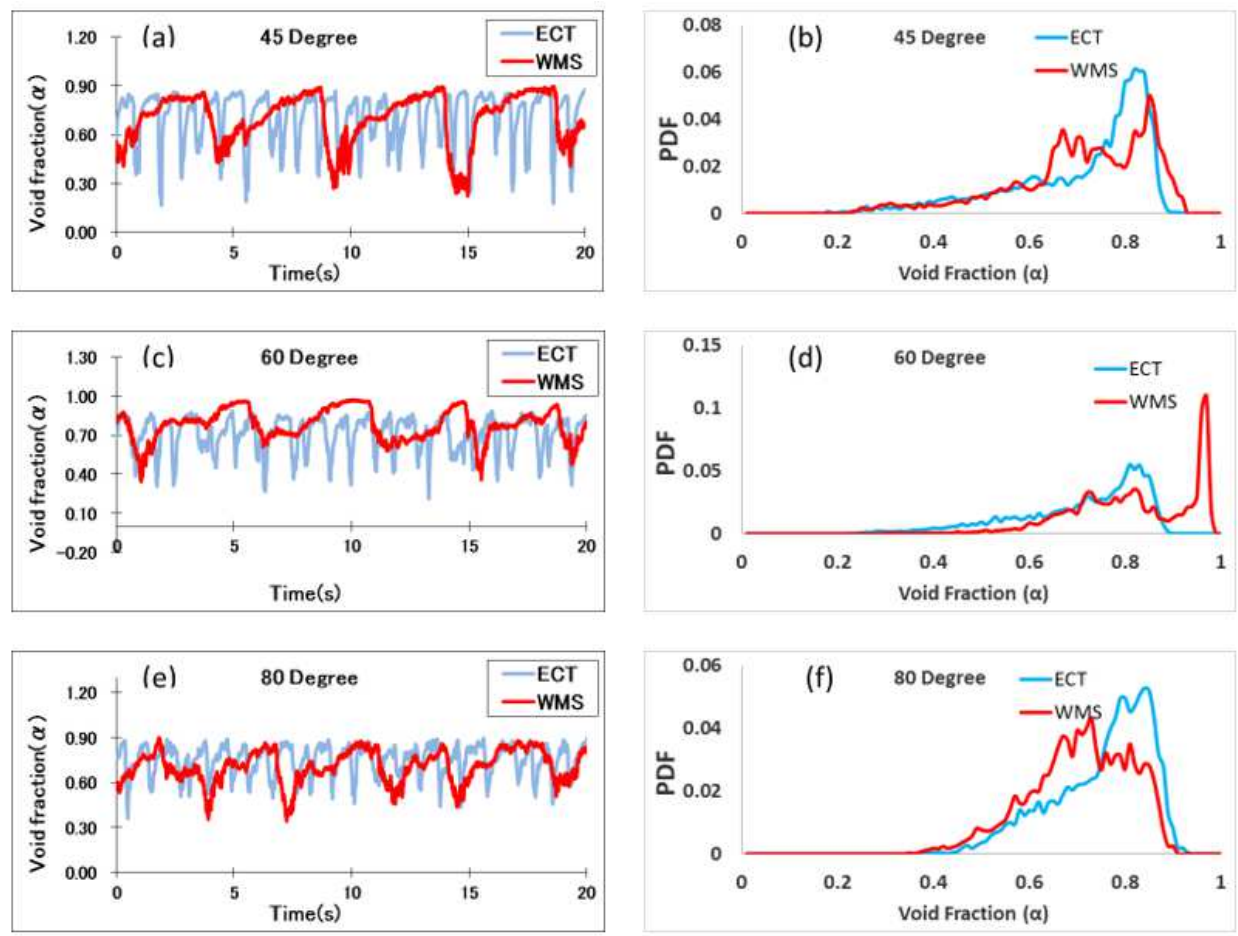

Figure 5: Void fraction of time series, and PDF technique for pipe orientations; 45-degree (a and b), 60 -degree (c and d), and 80-degree (e and f) respectively atUs1 $0.052 \mathrm{~m} / \mathrm{s}$ and Usg $2.5 \mathrm{~m} / \mathrm{s}$. 

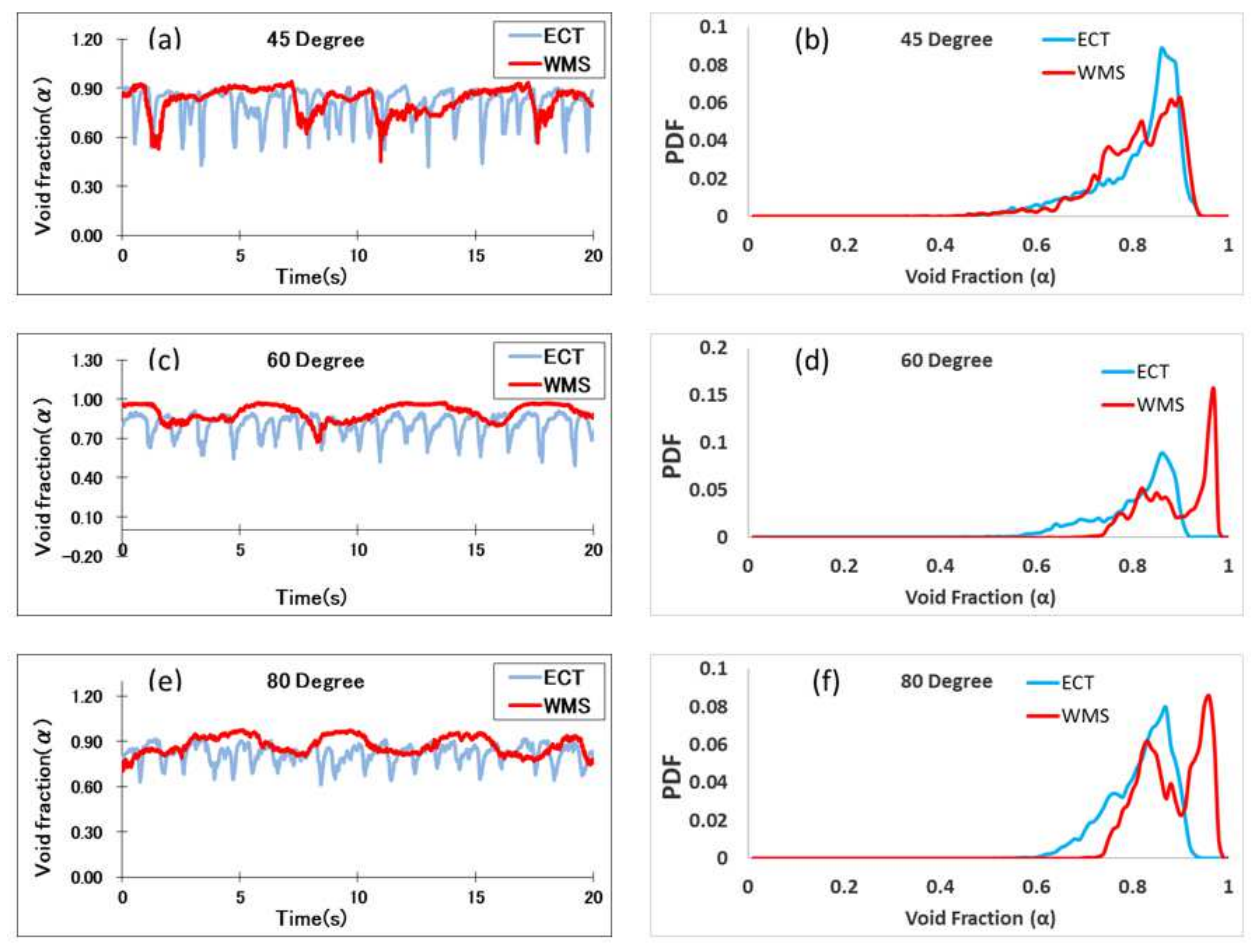

Figure 6: Void fraction of time series, and PDF technique for pipe orientations; 45-degree (a and b), 60-degree (c and d), and 80-degree (e and f) respectively at Usl $0.052 \mathrm{~m} / \mathrm{s}$ and Usg $4.7 \mathrm{~m} / \mathrm{s}$.

At constant Us1 $0.524 \mathrm{~m} / \mathrm{s} ;$ when the value of Us1 is increased to $0.524 \mathrm{~m} / \mathrm{s}$ and the started the value of Usg $0.05 \mathrm{~m} / \mathrm{s}$ as Figure 7 depicted. The plots of sections (a, b,d, and c) showed similar behaviour for both sensors, where the void fractions fluctuated near between 0.05 and 0.25 . The PDF plots recorded Wight base was ranged from 0 to 0.1 of void fraction and presented one big peak at a value of 0.3 . this section has a bubbly flow pattern. Where, the plots of sections (e and $f$ ) seen the similar value of both the sensors, the void friction wave near o and some peak near 0,1 .the pdf plot base was ranged 0 to 0.05 of void fraction and one peak at a value of 0.6 . the section as a bubbly flow pattern.

When the value of Usg is increased to $0.3 \mathrm{~m} / \mathrm{s}$ as Figure 8 described. The plots and figures of all sections seen similar behaviour for both sensors, where the void fractions fluctuated near between 0.2 and 0.8. The PDF plots recorded Wight bases were ranged from 0.1 to 0.7 of void fraction and presented two peaks at values of 0.02 and 0.065 . The babbly flow pattern altered to slug flow.

When the value of Usg value reached $1.5 \mathrm{~m} / \mathrm{s}$ depicted as in Figure 9, the pattern is noticed as churn flow of both sensors at all orientation angle inclined pipe flow in contrast with the churn flow that observed at the changing angle of the inclined flow line. The churn flow is characterized by the time series method when the mean void fraction $(\alpha)$ fluctuates at very high $(\alpha)$ values near to 0.65 void fraction $(\alpha)$ of 0.7 showed the section a,c, and e and the PDF curve is showed one peak at 0.045 of PDF at void fractions $(\alpha) 0.7$ respectively (Figure 9 ( section $b$, d, and f). 

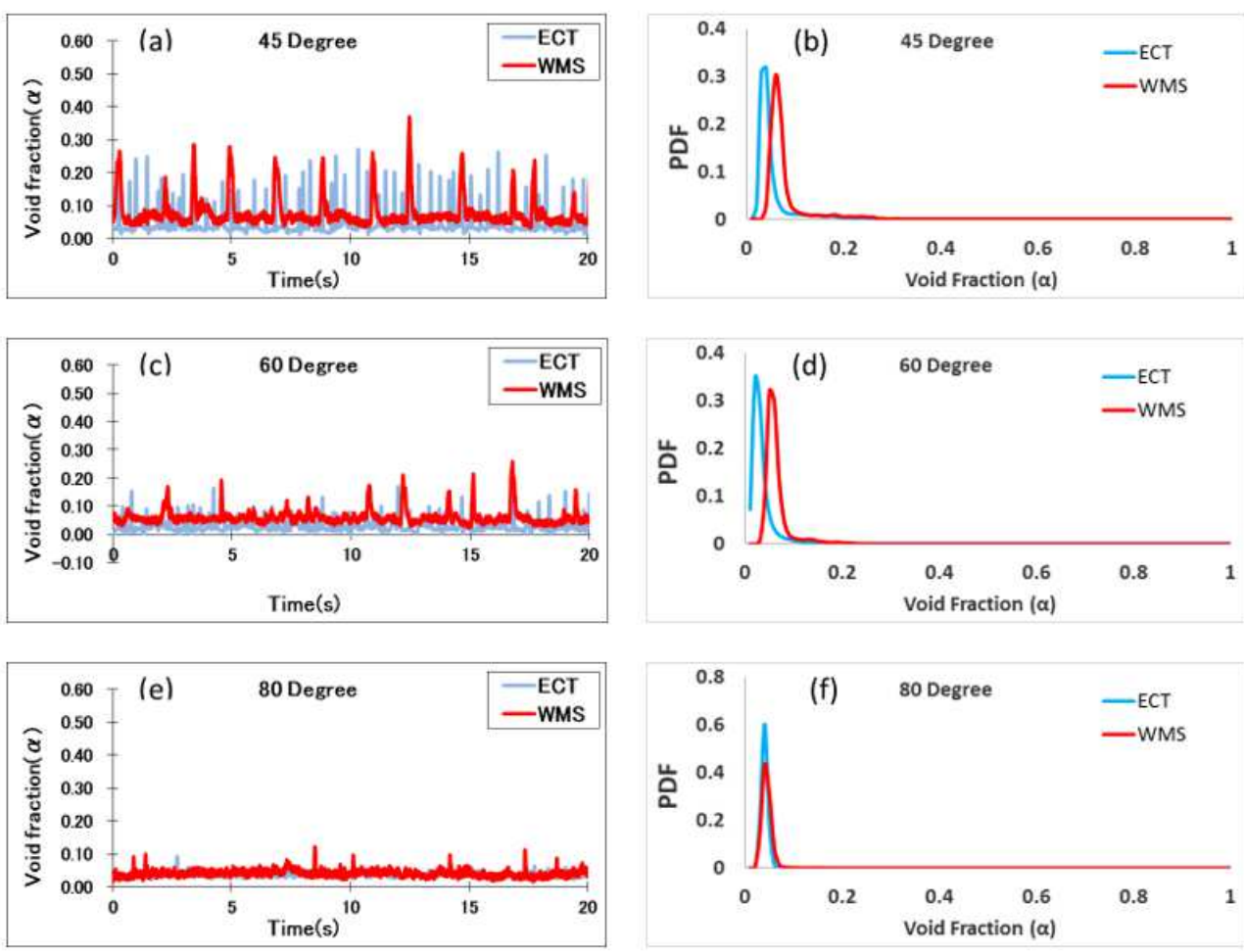

Figure 7: Void fraction of time series, and PDF technique for pipe orientations; 45-degree (a and b), 60 -degree (c and d), and 80-degree (e and f) respectively at Usl $0.524 \mathrm{~m} / \mathrm{s}$ and Usg $0.05 \mathrm{~m} / \mathrm{s}$
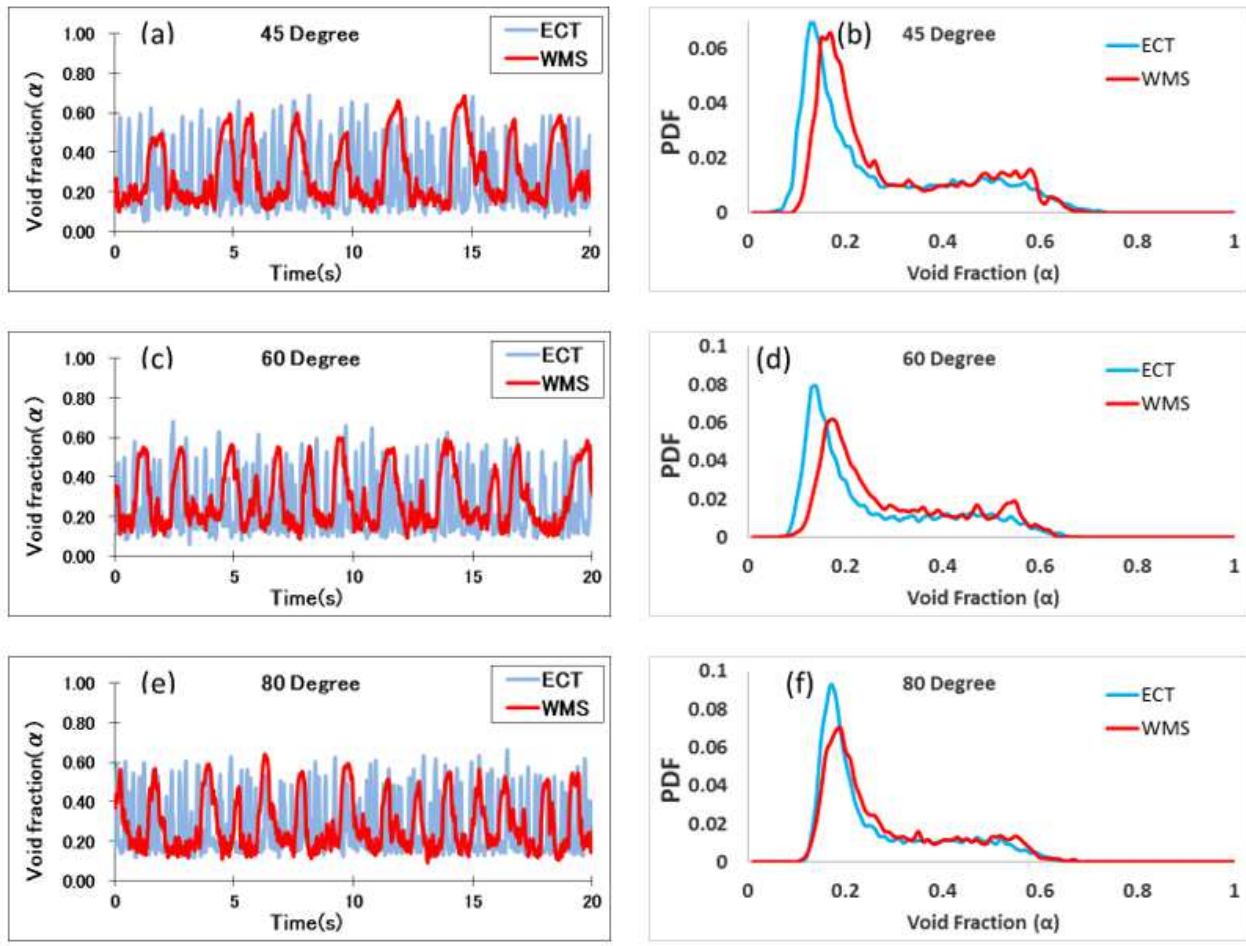

Figure 8: Void fraction of time series, and PDF technique for pipe orientations; 45-degree ( $a$ and $b$ ), 60 -degree (c and d), and 80-degree (e and f) respectively at Usl $0.524 \mathrm{~m} / \mathrm{s}$ and Usg $0.3 \mathrm{~m} / \mathrm{s}$ 

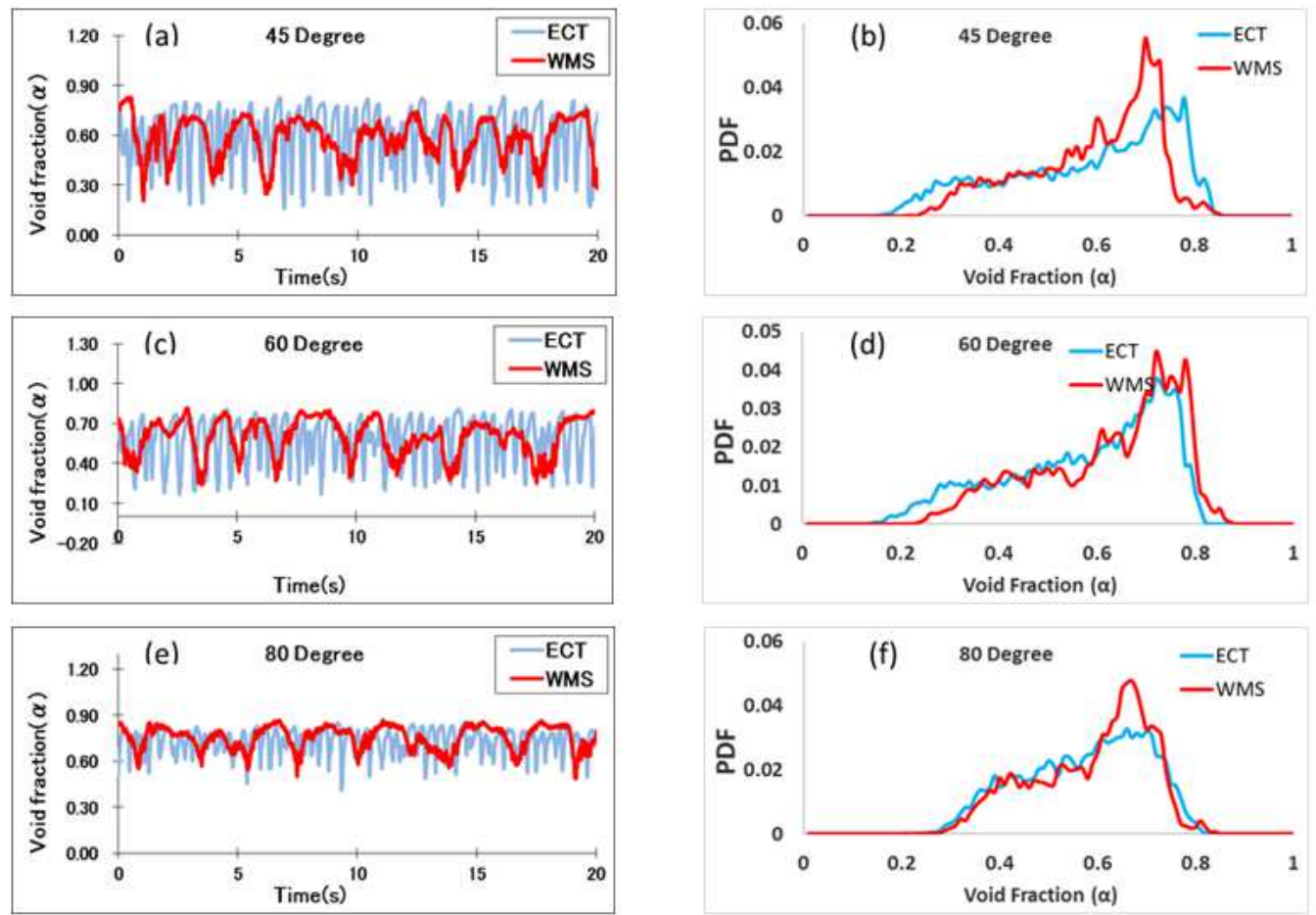

Figure 9: Void fraction of time series, and PDF technique for pipe orientations; 45-degree (a and $b$ ), 60 -degree (c and d), and 80-degree (e and f) respectively at Us1 $0.524 \mathrm{~m} / \mathrm{s}$ and Usg1.5 m/s

After that more in increased Usg from 1,5 to $4.7 \mathrm{~m} / \mathrm{s}$. the flow pattern was not changed also as churn flow shows the Figure 10. The churn flow is characterized by the time series method when the mean void fraction $(\alpha)$ fluctuates at very high $(\alpha)$ values near to 0.9 void fraction, showed the section a,c, and e and the PDF curve is showed one peak at 0.04 of PDF at void fractions $(\alpha) 0.8$ respectively (Figure 10 ( section b,d, and $\mathrm{f}$ ). This observation agrees with other works, HernandezPerez[21], andKokal and Stanislav[22], they found that for the situation of inclined upward flow, the force of gravity, for all ranges of gas and liquid flow rates, the intermittent flow will be repeated in the pipe, whereas stratified flow dominates in downward inclined pipes. 

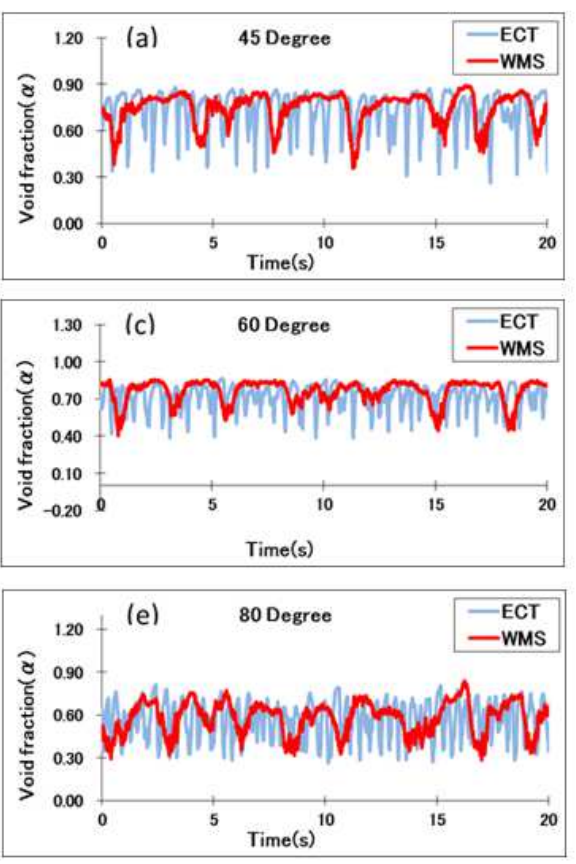
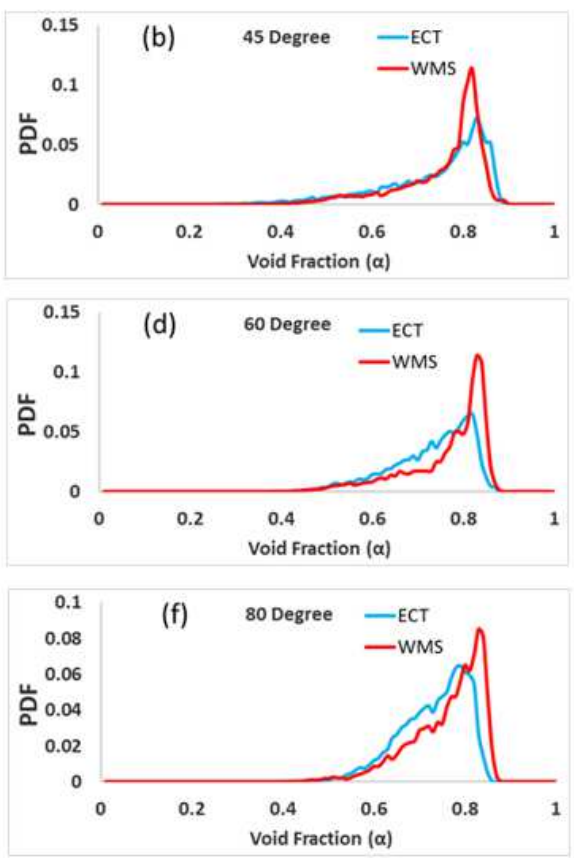

Figure 10: Void fraction of time series, and PDF technique for pipe orientations; 45-degree (a and b), 60-degree (c and d), and 80-degree (e and f) respectively at Us1 $0.524 \mathrm{~m} / \mathrm{s}$ and Usg from 1.5 to $4.7 \mathrm{~m} / \mathrm{s}$

\subsection{Mean Void Fraction:}

The mean void fraction shows the difference of the void fraction with a superficial velocity of the gas. The value that is obtained from the void fraction is necessary for other parameters, such as frequency, probability density function, PSD, and time series. many researchers of two-phase flow utilizing WMS or ECT are focused on phase allocation, however, more information was received. In more situations, it needs to know the mean value of gas or liquid volume fraction. the average void fraction is calculated for different runs at several flow conditions and different inclinations angles.

Figure 11 see the plots of the mean void fraction for the constant Usl as: 0.052 , and $0.524 \mathrm{~m} / \mathrm{s}$ with Usg values ranged from 0.05 to $4.7 \mathrm{~m} / \mathrm{s}$ at the 45 -degree inclined pipe flow using both sensors ECT and WMS Comparison between them. It emerges that the mean void fraction increases by raising the values of Usg at all conditions in all sections, see both linesWMS and ECT is the same line. However, there are some minor differences.

Figures 12 and 13, The average void fraction value supported the work by making a chart. By comparing this chart with other parameter charts, it is observed that the transitions in the line agree with the transition points that are obtained from other parameters, each point is related to a type of flow pattern and this supports this work. It shows where a rising void fraction with gas superficial velocity can be observed. Though these outcomes are useful and needed for many engineering calculations. The data and results of all of these instruments are shown to agree on the overall averaged over time and cross-section void fraction. However, there are some minor differences.

Also, in Figure 14 seen the mean void fractions from both techniques' WMS and ECT for different inclination angles as 45,60 , and 80 -degree. The graph illustrates the excellent agreement between the two methods of measurement. 
Figure 11: Mean void fractions plots with Usg rates for WMS and ECT in 45-degree inclined pipe atUsl; (A) 0.052, and (B) $0.524 \mathrm{~m} / \mathrm{s}$.
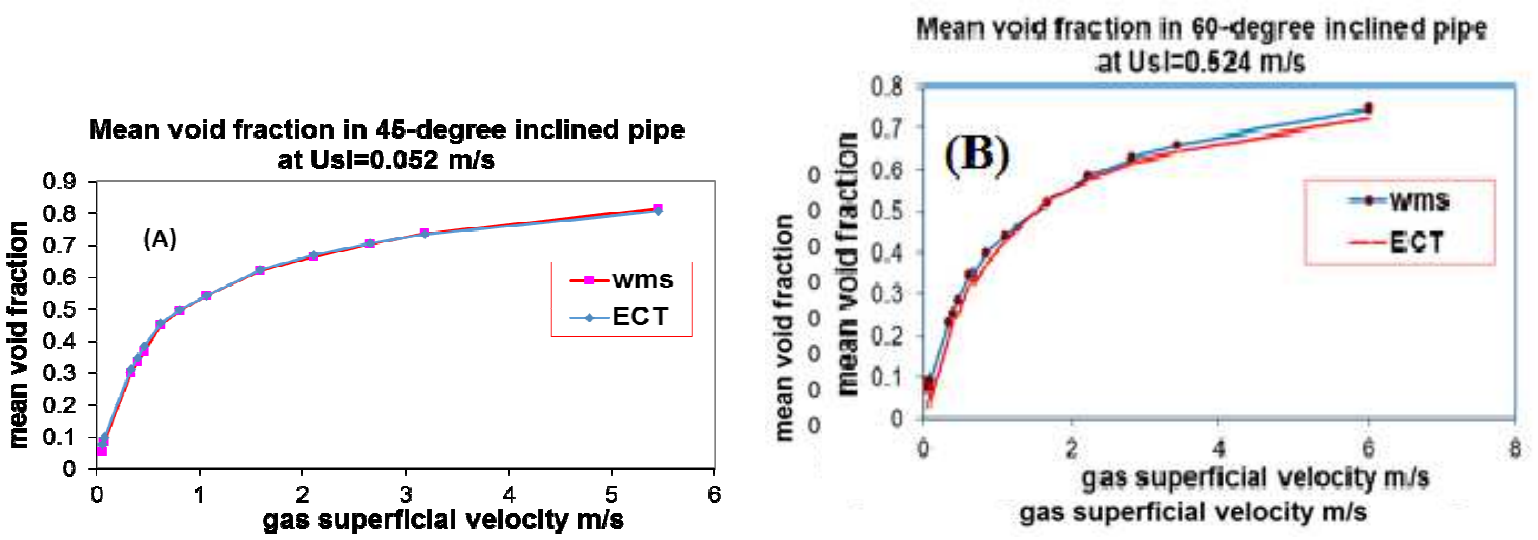

Figure 12: Mean void fractions plots with Usg rates for WMS and ECT in 60-degree inclined pipe at Usl; (A) 0.052, and (B) $0.524 \mathrm{~m} / \mathrm{s}$.

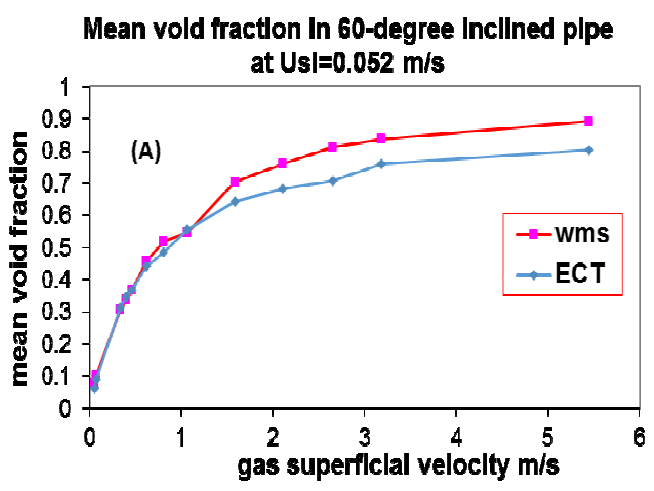



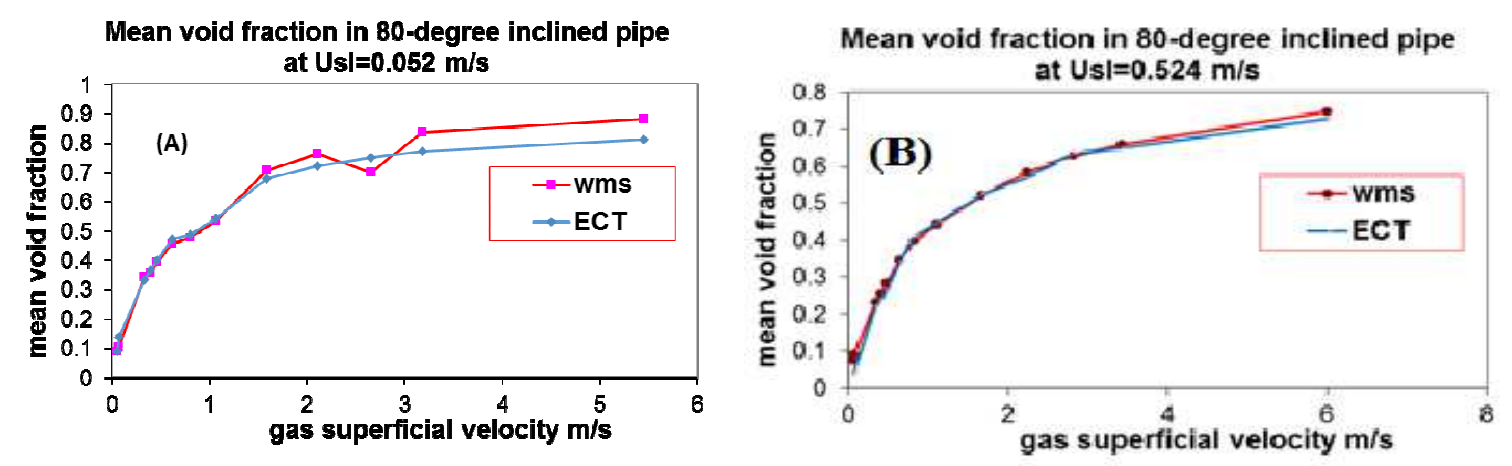

Figure 13: Mean void fractions plots with Usg rates for WMS and ECT in 80-degree inclined pipe at Usl; (A) 0.052 , and (B) $0.524 \mathrm{~m} / \mathrm{s}$.
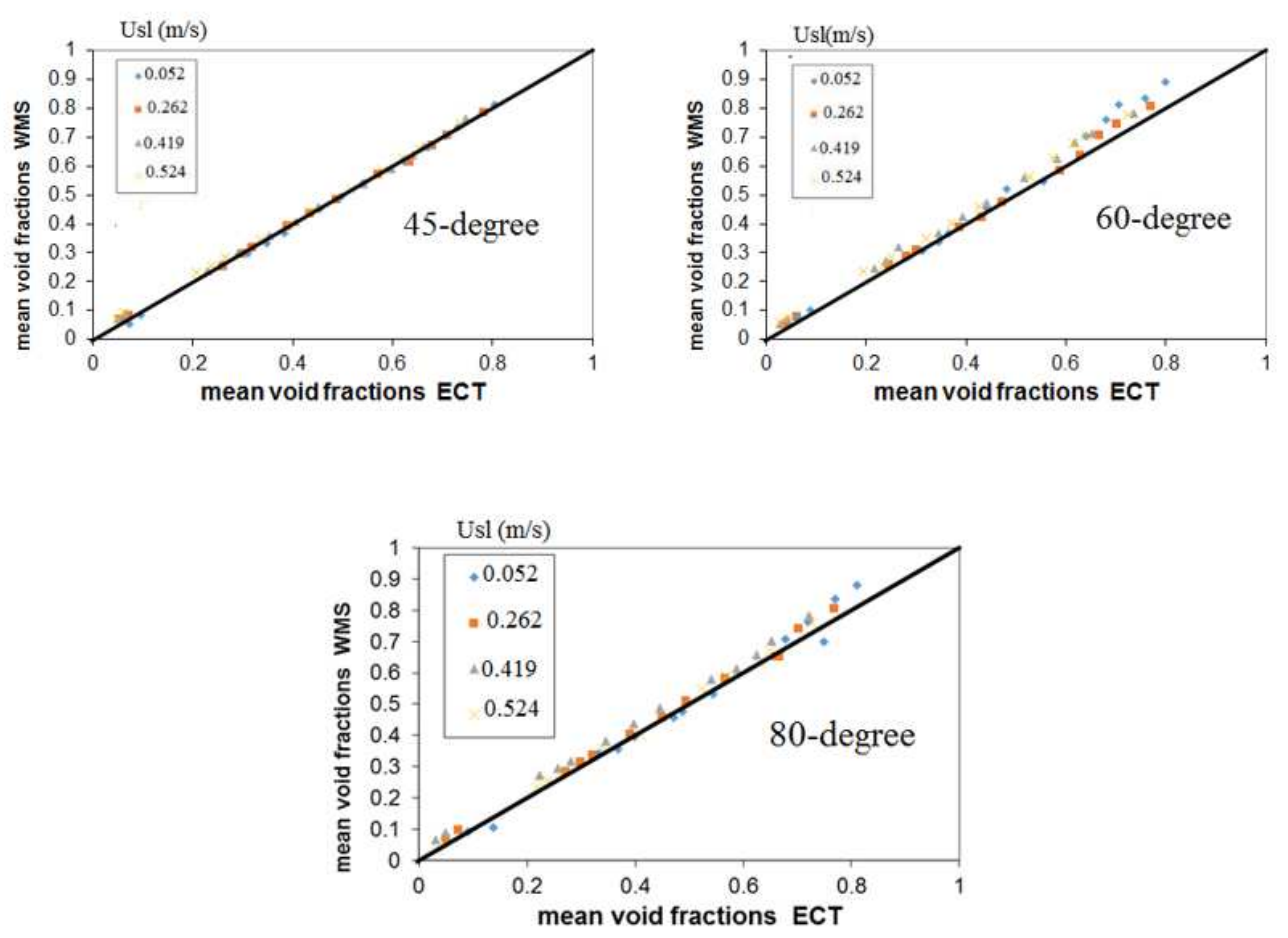

Figure 14: Comparison of overall mean void fraction from ECT and WMS for different inclination angles as (45-60, and80), and different Us1 and Usg.

\section{Conclusion}

The Investigation of liquid-gas two-phase flow in inclined pipes with the orientations of 45, 60 , and 80 degrees have been successfully performed in the current study using the following measurement sensors; Wire Mesh Sensor (WMS) and Electrical Capacitance Tomography (ECT). Cross-sectional void fraction values of the oil-gas mixture are analyzed utilizing time series with void fraction correlations, tomographic images obtained from the WMS program, and probability density function (PDf), mean void fraction analysis. The present experiment is tested under liquid superficial 
velocities were ranged from 0.052 to $0.524 \mathrm{~m} / \mathrm{s}$ and gas superficial velocities were altered from 0.05 to $4.7 \mathrm{~m} / \mathrm{s}$. Also, a comparison is conducted from the outcomes of both sensors to declared the similarities and the differences between them. In addition, the present results are contracted with the results of the previous researches. Finally, the bold results obtained from the current empirical test are stated below:

- The estimated flow patterns of two-phase flow were observed from the present investigation at the different test conditions agreed with the results identified by the researchers in $[1,10,19]$.

- The measurement techniques employed in this study are powerful to use in gas-liquid void fraction measurements.

- The Comparison between the Wire Mesh Sensor (WMS) and Electrical Capacitance Tomography (ECT) was determined and the results were revealed that both sensors gave similar results, despite, the WMS has a higher frequency was calculated 1000 frames per second compared with the ECT which worked at 100 frames per second.

- The void fraction of the two-phase flow, PDF, and tomographic images techniques have been used to identify the flow pattern such as bubbly, slug, and churn were very useful for providing details about the regime's flow.

- The gas flow rate is increased steeply at a constant liquid value from 0,05 to $4.7 \mathrm{~m} / \mathrm{s}$, where at Usg value is recorded $0.05 \mathrm{~m} / \mathrm{s}$, bubbly flow is observed, at Usg values reached to $0.3 \mathrm{~m} / \mathrm{s}$, the slug flow pattern is classified. Finally, when the Usg is boosted more to $1.3 \mathrm{~m} / \mathrm{s}$, churn flow occurred at different pipe orientations.

- The increment that added to the liquid flow rate values did not affect directly on the flow patterns, whereas, the value of the gas flow rate impacted significantly on the patterns.

\section{References}

[1] L. A. Abdulkareem, E. Escrig, B. N. Reinecke, S. Hewakandamby, and B. J. Azzopardi, "Tomographic interrogation of gas-liquid flows in inclined risers," in ICMF-2016 - 9th International Conference on Multiphase Flow, 2016.

[2] A. Mešić, I. Delić, and N. Ganibegović, "Numerical modeling of multiphase flow inside aeromixture channel and low emission burner of boiler OB-650," Technium: Romanian Journal of Applied Sciences and Technology, vol. 2, no. 7, pp. 94-106, 2020, doi: 10.47577/technium.v2i7.1649.

[3] I. Martic, A. Maslarevic, N. Milovanovic, and M. Markovic, "Effect of baffle cut and baffle spacing on pressure drop in shell and tube heat exchanger with U tubes," Technium: Romanian Journal of Applied Sciences and Technology, vol. 2, no. 2, pp. 72-78, 2020, doi:

[4] Mahmood, R.A., D. Buttsworth, and R. Malpress, Experimental and Numerical Investigation of Two-phase Flow Orientation Direction Change on a Vertical Flash Tank Separator. International Journal of Management and Applied Science (IJMAS), 2019. 5(4): p. 25-29.

[5] Mahmood, R., D. Buttsworth, and R. Malpress, Computational and Experimental Investigation of using an Extractor in the Vertical Gravitational Flash Tank Separator. International Journal of Automotive and Mechanical Engineering, 2019. 16(2): p. 6706-672

[6] Mahmood, R.A., D. Buttsworth, and R. Malpress, Computational and Experimental Investigation of the Vertical Flash Tank Separator Part 1: Effect of Parameters on Separation Efficiency. International Journal of Air-Conditioning and Refrigeration, 2019

[7] H. M. Prasser, A. Böttger, and J. Zschau, "A new electrode-mesh tomograph for gas-liquid 
flows," Flow Meas. Instrum., vol. 9, no. 2, pp. 111-119, 1998.

[8]M. G. Rasteiro, R. Silva, F. A. P. Garcia, and P. Faia, "Electrical tomography: a review of configurations and applications to particulate processes," KONA Powder Part. J., vol. 29, no. 29, pp. 67-80, 2011.

[9] U. Hampel, M. Speck, H. J. Menz, D. Hoppe, E. Schleicher, and H. M. Prasser, "Experimental ultra fast x-ray computed tomography with a linearly scanned electron beam source," Flow Meas. Instrum., vol. 16, no. 2-3, pp. 65-72, 2005.

[10]Y. Murai, S. Ohta, A. Shigetomi, Y. Tasaka, and Y. Takeda, "Development of an ultrasonic void fraction profiler," Meas. Sci. Technol., vol. 20, no. 11, 2009.

[11]L. A. Abdulkareem, S. Sharaf, B. J. Azzopardi, and A. Hunt, "Effect of Inclination on Slug Flow Characteristics," Proceedings of the ASME 2010 International Mechanical Engineering Congress \& Exposition, pp. 735-742, 2010, doi: 10.1115/IMECE2010-38119.

[12]V. A. Musa, R. A. Mahmood, S. M. N. Khalifa, O. M. Ali, and L. A. Abdulkareem, "Flow Patterns of Oil-Gas and Pressure Gradients in Near-Horizontal Flow Pipeline : Experimental Investigation Using Differential Pressure Transducers," vol. 39, no. 2, pp. 621-628, 2021

[13] O. T. Kajero, M. Abdulkadir, L. Abdulkareem, and B. J. Azzopardi, "Experimental study of viscous effects on flow pattern and bubble behavior in small diameter bubble column," Physics of Fluids, vol. 30, no. 9, pp. 93101(1-16), 2018, doi: 10.1063/1.5045160.

[14] Jones, Jr. O. C. and Zuber, N., (1975), "The Interrelation between Void Fraction Fluctuations and Flow Pattern in Two-Phase Flow”, International Journal of Multiphase Flow, Vol. 2, pp. 273306.

[15]L. A. Abdulkareem, V. A. Musa, R. A. Mahmood, and E. A. Hasso, "ExperimentalInvestigation of Two-Phase Flow Patterns in a Vertical to Horizontal Bend Pipe Using Wire-Mesh Sensor," Revista de Chimie, vol. 71, no. 12, pp. 18-33, 2021, doi: 10.37358/rc.20.12.8383.

[16] Xei, C.G., et al (1989), "Eight Electrode Capacitance System for Two-component Flow Identification”, IEE proceeding Pt. A, 136, pp. 184-190.

[17] Xie, C. G., et al (1995), "Electrical Tomography Techniques for Process Engineering Applications", Chemical Engineering Journal, Vol. 56, pp. 127-133.

[18]Williams, R. A. and Beck, M. S., (1995), "Process Tomography Principles, Technique and Application", Butterworth-Heinemann, Oxford.

[19] Azzopardi B.J., et al (2008), "Wire Mesh Sensor Studies in a Vertical Pipe" Fifth International Conference on Transport Phenomena in Multiphase Systems, Bialystok, Poland.

[20]V. A. Musa, L. A. Abdulkareem, and O. M. Ali, "Experimental Study of the Two-Phase Flow Patterns of Air-Water Mixture at Vertical Bend Inlet and Outlet," Engineering, Technology \& Applied Science Research, vol. 9, no. 5, pp. 4649-4653, 2019, doi: 10.48084/etasr.3022.

[21] Hernandez Perez, V., (2008), "Gas-Liquid Two-Phase Flow in Inclined Pipes", Ph.D. Thesis, The University of Nottingham, UK

[22] Kokal, S. L. and Stanislav, J. F., (1989), “An Experimental Study Of Two-Phase Flow in Slightly Inclined Pipes ", Chemical Engineering Science, Vol. 44, No. 3, pp. 681-693 